MATEC Web of Conferences 19, 01035 (2014)

DOI: $10.1051 /$ matecconf/ 20141901035

(C) Owned by the authors, published by EDP Sciences, 2014

\title{
Evaluation Different Boundary Condition in Depth of Tissue for the Task of Mathematical Simulation of Heat Transfer in Human Skin
}

\author{
Dariya V. Korobkina and Nikolay V. Baranovskiy ${ }^{a}$ \\ National Research Tomsk Polytechnic University, 634050 Tomsk, Russia
}

\begin{abstract}
The problem of an estimation of thermal defeats at influence of affected factors of fire has great value for various areas of technics, industry and medicine. Results of mathematical simulation of heat transfer in layered structure of human skin influenced by the radiant thermal flux of the set value are presented in the work. The three-layer system of skin is considered. Research according to the various boundary conditions exposed in human tissue is carried out. Temperature distribution on thickness of skin is presented.
\end{abstract}

\section{Introduction}

For an estimation of consequences of influence of thermal radiation in extreme situations (including, forest fires [1]) both domestic and foreign methods which represent quantitative dependences between thermodynamic and medical criteria of thermal defeat can be applied [2,3]. There are no program components realizing developed mathematical models of real thermophysical processes, occurring in human skin and tissue now. The present project opens prospects of creation of new generation of medical information systems [4-6] for needs of the Ministry of Emergency Measures and the first help at minimization and liquidation of a social damage from forest fires.

Great volume of experimental data on thermal burns of various severity level of bioobject is saved up in leading research in Centers of NASA. Results of experimental researches have served as a basis for creation of standard estimation methods of bioobjects defeat. Following methods of forecasting [710]) are marked (1) experimental; 2) calculus 3) calculus-experimental) after carried harmonization of domestic and foreign methods for forecasting of thermal defeat for system «thermal source - clothes package - human»

The purpose of the present work is mathematical simulation of heat transfer in layered structure of human skin taking into account statement of various boundary conditions in depth of human tissue.

\section{Physical and Mathematical Statement}

The skin has rather difficult structure having the features in various parts of a body. The skin consists of three layers: epidermis, derma and hypodermis, as is shown in fig. 2 [7]. Epidermis consists basically of dead cages which operate as a protective barrier against moisture, ultra-violet radiation and heats [8]. Through epidermis pass sweat glands. The thickness of epidermis is various:

\footnotetext{
${ }^{a}$ Corresponding author: firedanger@narod.ru
} 
from 0,02 to $0,05 \mathrm{~mm}$ on a neck and to $0,5-2,4 \mathrm{~mm}$ on palms and soles. The bottom layer of epidermis is basal and it lays on basal membrane dividing epidermis and derma. In basal layer there are cylindrical cages which it is constant, in the course of cellular division fill the become horny layer [9]. Derma is basic part of a skin. It much more thickly also comprises blood vessels, nervous endings, sebaceous glands and roots of hair. The thickness of derma varies from $0,5 \mathrm{~mm}$ to $5 \mathrm{~mm}$. Two layers allocate in derma: papillary and reticular. In papillary layer there are various fibres giving to a skin durability and elasticity, and also numerous blood and lymphatic vessels, nervous textures and endings. The reticular layer settles down under papillary layer. Sweat and sebaceous glands, hair follicles is lie in this layer. Channels of sebaceous glands open in hair follicles. Fibrous structures of derma consist from collagenic, elastic and reticular fibres. Intervals between fibres, appendages of a skin and other structural formations are occupied with so-called basic substance - an amorphous substance [9]. Epidermis and derma, together taken, have a thickness about 1-2 mm. Below these two layers the hypodermic tissue which contains sweat glands and large blood vessels which give the chance to a skin to adapt to local heating or cooling, but only in certain limits [10]. It consists of a friable network collagenic, elastic and reticular fibres in which loops segments of a fatty tissue are located. The hypodermic is penetrated by a network of nerves and blood vessels which support and feed derma and epidermis. The thickness of this layer is various and depends on a way of life of the person, food and metabolism [9].

Usually skin subdivide into two types - thick and thin, that is connected, mainly, with various thickness of epidermis. The thick skin covers palms and soles. For it presence thick epidermis on which external surface especially powerful layer of keratin settles down is characteristic. In skin covering other parts of body, epidermis rather thin, and its external become horny layer also rather thin. On some sites of body which are exposed to pressure (on back, on buttocks, on back surfaces of hips), is available thick derma. The thickness of skin depends on sex, age, color, state of health and localization $[11,12]$. The integument structure is resulted on fig. 1.

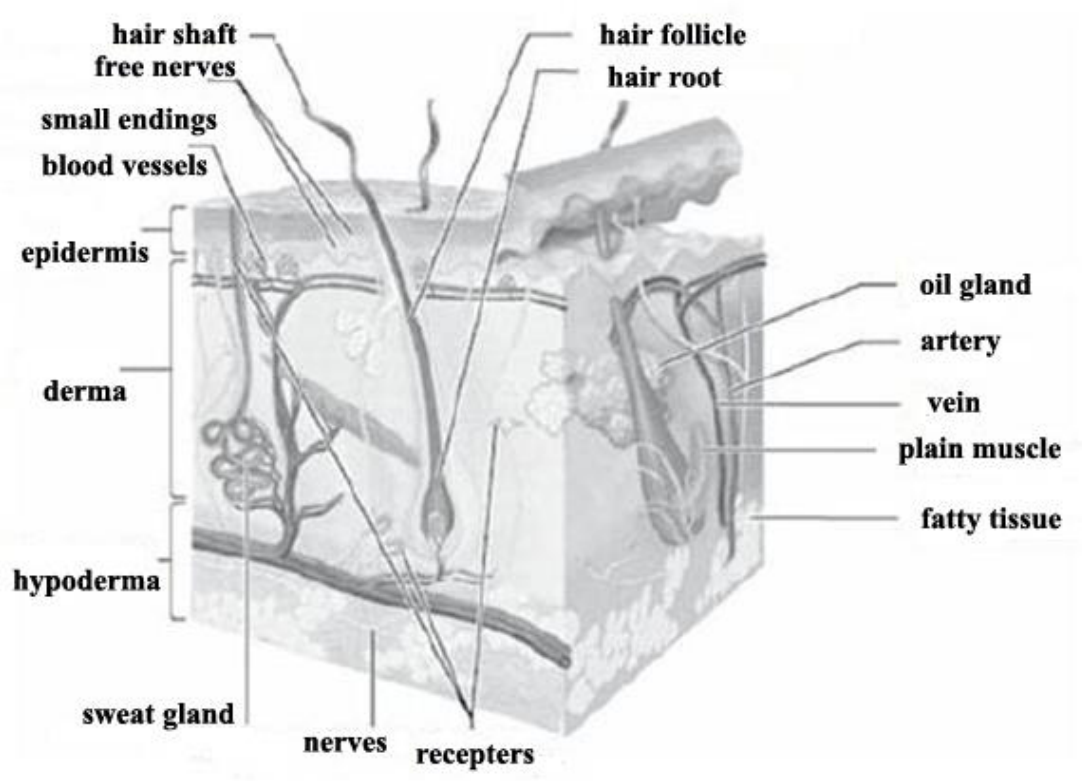

Figure 1. Structure of human skin [12]. 
Among the basic functions of a skin it is possible to allocate following [13]:

- protective (protects an organism from action of mechanical and chemical factors, ultraviolet radiation, penetration of microbes, losses and hits from the outside of water, the horn layer of epidermis provides a barrier of an evaporating liquid, prevents swelling and skin shrinkage);

- thermal control;

- participation in water-salt exchange;

- excretory (ejection products of an exchange, salts, medicines);

- blood deposition (in skin vessels can be to one liter of blood); hormones);

- endocrine and metabolic (synthesis and accumulation of vitamin D and some

- receptor (presence of the numerous nervous endings);

- immune (capture, processing and transport of antigenes with the subsequent progress of immune reaction);

- protection against an ultra-violet irradiation;

- sensitive function (skin cause various kinds of sensations (tactile, pressure, heat, cold and pain);

- resorption function;

- respiratory function (oxygen arrives and carbonic acid is ejected through a skin) [12].

Thus, the skin is the major part which is carrying out a number of unique functions in a human body. With a view of mathematical simulation, the skin of the person can be considered as layered structure agreed on fig. 2 .

We use the approach of mathematical simulation for research of influence of fire front and its damaging factors on human skin. We will consider one-dimensional three-layer model of a skin in which heat is transferred by means of heat conductivity. The geometry of the decision area for our task is presented on fig. 2 .

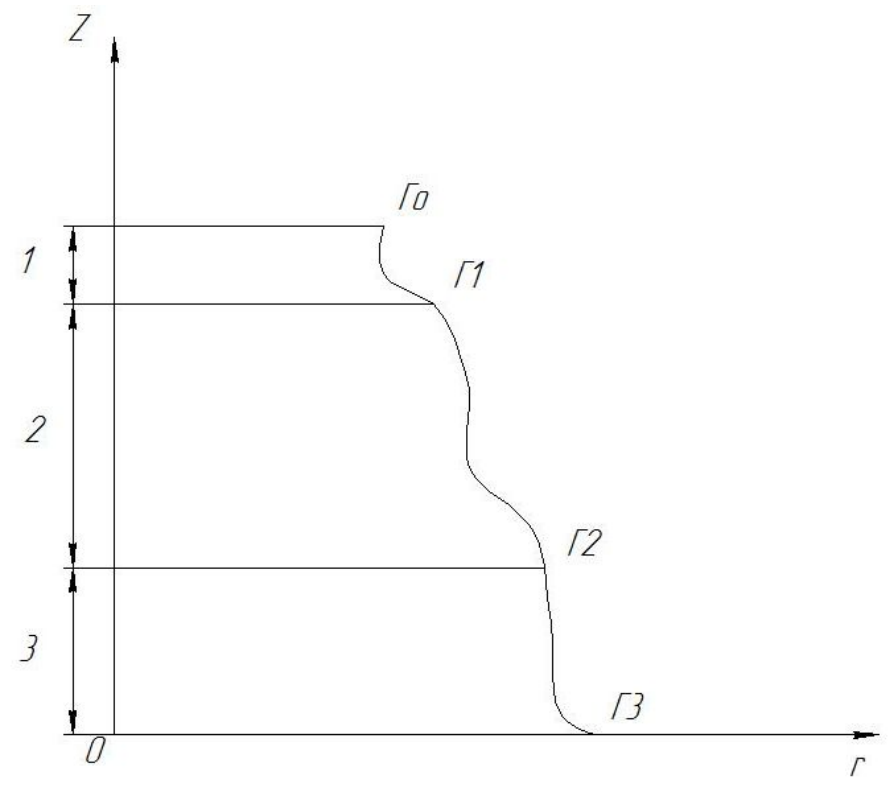

Figure 2. Scheme of decision area.

Mathematical modelling is shown to the decision of system of the non-stationary equations of heat conductivity for system «epidermis - derma - hypodermis» with corresponding boundary and initial conditions. 


\section{MATEC Web of Conferences}

The temperature field in each layer is described by the differential equation of heat conductivity:

$$
\begin{aligned}
& c_{1} \rho_{1} \frac{\partial T_{1}}{\partial t}=\lambda_{1} \frac{\partial^{2} T_{1}}{\partial z^{2}}, \\
& c_{2} \rho_{2} \frac{\partial T_{2}}{\partial t}=\lambda_{2} \frac{\partial^{2} T_{2}}{\partial z^{2}}, \\
& c_{3} \rho_{3} \frac{\partial T_{3}}{\partial t}=\lambda_{3} \frac{\partial^{2} T_{3}}{\partial z^{2}} .
\end{aligned}
$$

Where $T_{i}, c_{i}, \rho_{i}, \lambda_{i}$ - temperature, specific thermal capacity, density, heat conductivity $(1,2,3-$ epidermis, derma, hypodermis).

Initial and boundary conditions:

$$
t=0, T_{i}=T_{0}
$$

It is applied boundary conditions of 2 nd sort on border $\Gamma 0$ since we consider influence of thermal flux from fire front:

$$
\Gamma 0: \quad \lambda_{1} \frac{\partial T_{1}}{\partial z}=q_{f},
$$

Where $q_{f}=f(\mathrm{x}), x$ - distance from a fire front; $q_{f}$ - thermal flux from fire front.

It is used boundary conditions of 4 th sort on borders $\Gamma 1$ and $\Gamma 2$ :

$$
\begin{aligned}
& \Gamma 1: \quad T_{1}(t, z)=T_{2}(t, z), \\
& -\lambda_{1} \frac{\partial T_{1}}{\partial z}=-\lambda_{2} \frac{\partial T_{2}}{\partial z}, \\
& \Gamma 2: \quad T_{2}(t, z)=T_{3}(t, z), \\
& -\lambda_{2} \frac{\partial T_{2}}{\partial z}=-\lambda_{3} \frac{\partial T_{3}}{\partial z},
\end{aligned}
$$

We will be set 3 various conditions on border $\Gamma 3$ :

1) $\quad T_{3}=T_{3 i}$; Temperature of internal part of hypodermis;

2) $\lambda_{3} \frac{\partial T_{3}}{\partial z}=q_{\text {int }} ; q_{\text {int }}$ - thermal flux of an internal organism part (an internal thermal emission),

3) $\quad \alpha\left(T_{e}-T_{3}\right)=\lambda_{3} \frac{\partial T_{3}}{\partial z}$; It is used heat transfer factor.

The finite difference method has been used for numerical realization of the offered model. Difference analogues of the one-dimensional equations dared by marching method in combination to method of simple iteration. The program component has been developed for numerical modelling of heat transfer in structurally non-uniform skin layer in high level language Object Pascal.

\section{Results and Discussion}

Comparative results for 3 various conditions are presented on fig. 3. The analysis of results allows to draw a conclusion that at the decision of such problems the choice of a kind of boundary conditions on internal border of settlement area is not basic in case of small values of thermal fluxes from forest fire front [14]. That is it is justified at rather long distances from fire front to the person. It is necessary to investigate this question in addition in case of intensive thermal flux. 


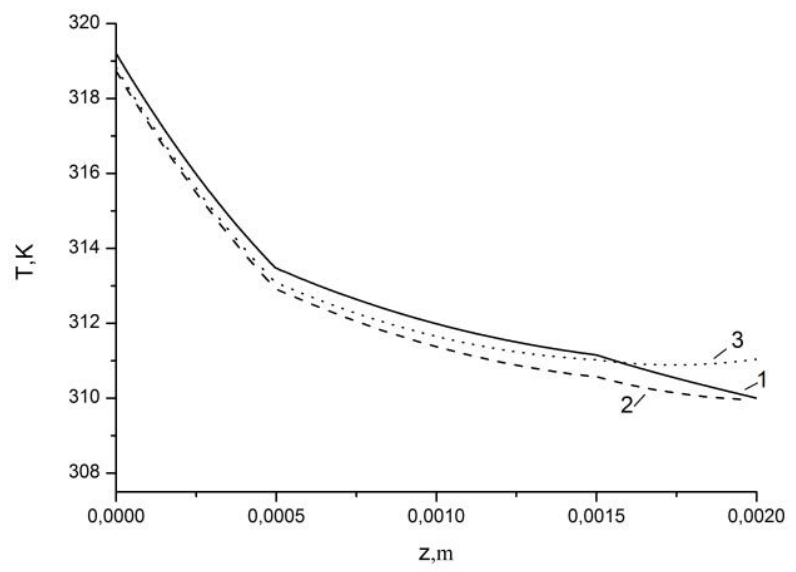

a

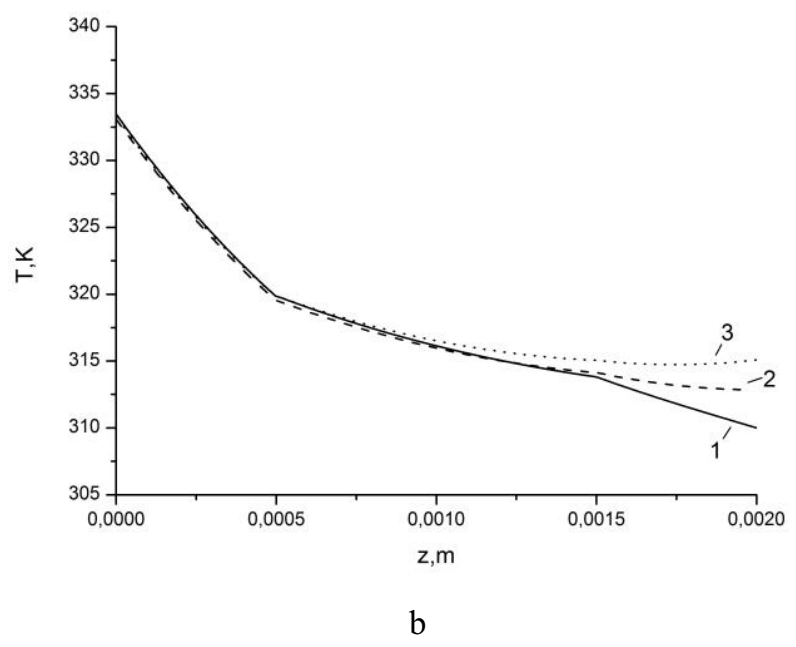

Figure 3. Temperature distribution in layered skin after 10 seconds of thermal flux influence from fire front: a) $q_{\mathrm{f}}=3000 \mathrm{~W} / \mathrm{m}^{2}$; b) $q_{\mathrm{f}}=7000 \mathrm{~W} / \mathrm{m}^{2}$.

The qualitative analysis of the obtained results allows to draw a conclusion, that the fullest coordination of numerical calculations with physical representations about heat transfer processes in layered skin of the person correspond to the second variant. It is necessary to use boundary conditions of 2 nd sort with the set internal thermal emission in tissues of the person at mathematical simulation of such processes. During too time at small values of thermal fluxes from forest fire front the researcher is free in a choice and statement of boundary conditions on internal border of human skin.

\section{Conclusion}

The analysis of results allows to draw conclusion that at the decision of such problems the choice of a kind of boundary conditions on internal border of decision area is not basic in case of small values of thermal fluxes from front of forest fire [14]. That is it is justified at rather long distances from fire front to the person. It is necessary to investigate this question in addition in case of intensive thermal fluxes. 


\section{MATEC Web of Conferences}

Developing of the advanced mathematical models of heat transfer in layered skin of the person creates preconditions to design problem-oriented program components. Such program modules can be used in medical information systems. Probably cumulative application of such systems and the geographic information technologies [15-17] based on deterministic models of forest fire occurrence $[18,19]$. It will allow to developing monitoring systems of forest fires impact on the person in a mode which advances real time of accident progress.

\section{References}

1. G.V. Kuznetsov, N.V. Baranovskiy, Prognoz vozniknoveniya lesnikh pozharov $i$ ikh ekologicheskikh posledstviy, (2009) (In Russian)

2. R.Sh. Enaleev, A.M. Zakirov, J.S. Chistov, E.Sh. Telyakov, Vestnik Kazanskogo tekhnologicheskogo universiteta, 15, 50 (2012) (In Russian)

3. ASTM Standard D 4108-87, Standard test method for thermal protective performance of material for clothing by open flame method, American society for testing and materials (1994)

4. D.V. Korobkina, N.V. Baranovskiy, Cloud of Science, 1, 292 (2014) (In Russian)

5. S. Petter, A. Fruhling, International journal of medical informatics, 80, 480 (2011)

6. N. Bricon-Souf, C. Verdier, A. Flory, M.C. Jaulent, IRBM, 34, 9 (2013)

7. F. Xu, T.J. Lu, K.A. Seffen, Acta Mechanica Sinica, 24, 1 (2008)

8. A. Hummel, K. Lyons, Fire Technology, 50, 1285 (2014)

9. A.E. Pushkareva, Lazerniy selektivniy nagrev elementov kozhi. Diss. Cand. Tech. Sci. (2006) (In Russian)

10. B.A. Paramonov, Ya.O. Porembskiy, V.G. Yablonskiy, Ozhogi: Rukovodstvo dlya vrachey (2000) (In Russian)

11. J.T. Whitton, J.D. Everall, Br. J. Dermatol, 89, 467 (1973)

12. V.L. Bykov, Kozha i ee proizvodnie // Chastnaya gistologiya cheloveka (2001) (In Russian)

13. M.V. Vildieva, Obosnovanie primeneniya meksidapta $v$ kompleksnom lechenii bolnikh $s$ termicheskoy travmoy, Diss. Cand. Med. Sci. (2009) (In Russian)

14. E.N. Valendik, I.V. Kosov, Sibirskiy ecologicheskiy zhurnal, 4, 517 (2008) (In Russian)

15. E.P. Yankovich, N.V. Baranovskiy, $14^{\text {th }}$ International Multidisciplinary Scientific Geoconference SGEM - 2014. GeoConference on Informatics, Geoinformatics and Remote Sensing. Conference Proceedings (17 - 26 June 2014, Albena, Bulgaria), 1, 607 (2014)

16. N.V. Baranovskiy, E.P. Yankovich, Proceedings of 5th International Conference on Cartography and GIS (Riviera, Bulgaria, 15 - 20 june 2014). / Eds. T. Bandrova, M. Konecny. Sofia: Bulgarian Cartographic Association, 2, 756 (2014)

17. N.V. Baranovskiy, M.V. Zharikova, Lecture Notes in Geoinformation and Cartography $L N G \& C$. Thematic Cartography for the Society, 13 (2014)

18. G.V. Kuznetsov, N.V. Baranovskiy, EPJ Web of Conferences, 76 (01028), 1 (2014)

19. G.V. Kuznetsov, N.V. Baranovskiy, Proceedings of SPIE, 8890, paper 889011 (2013) doi:10.1117/12.2033929 